\title{
PALABRAS CULMINANTES EN \\ LA TRAGEDIA GRIEGA - HYBRIS
}

\author{
César García Álvarez \\ Universidad San Sebastián. Chile
}

Resumen: En este artículo el autor examina el término hybris y sus implicancias en la cultura griega, particularmente en la tragedia.

Palabras claves: Hybris- Tragedia

\section{CULMINANT WORDS IN THE GREEK TRAGEDY - HYBRIS}

Abstract: In this article the author has examined the concept hybris and its implications in the Greek culture, which is particularly noticeable in the tragedy.

Keywords: Hybris - Tragedy

Recibido: 6.09.18 - Aceptado: 15.01.19

Correspondencia: César García Álvarez.

Email: bizantinoscesar@gmail.com

Doctor en Filosofía con mención en Literatura. 
T as grandes obras -literarias, de pensamiento e incluso materiales- se sostienen conceptualmente sobre dos o tres palabras claves, se llaman éstas: palabras culminantes, fórmulas, ejes de estructura o en el caso del arte, "motivo" ya pictórico ya literario. Las tragedias -nos referimos a las griegas- no se sustraen a esta simplificación esencial: Tuxe, hybris, katharsis y epidemía, por ejemplo, sustentan el edificio de la literatura que un día Esquilo, Sófocles y Eurípides levantaron para la eternidad. Podrán añadirse otras palabras, como diké, sophrosyne o xoros, pero no muchas más. Me referiré en este estudio a hybris, término nuclear en la cultura griega ${ }^{1} \mathrm{y}$ desencadenante de la tragedia ${ }^{2}$.

\section{1.- La Edad de los Metales instauró en el mundo la hybris}

Toda tragedia se construye sobre la polaridad de un conflicto, siendo una de las fuerzas de este choque la que recibe el nombre de hybris ${ }^{3}$.

1 Si queremos saber del valor culminante de una palabra en una lengua, sometámosla a un análisis etimológico. En el caso de hybris, lo ha hecho Chantraine; observa que acepta las terminaciones en ios-eos (con ómicron)- eos (con omega). Aparece compuesto, aunque raramente, con hybrígelos; da lugar a verbos denominativos como hydriso; presenta siete formas derivadas registradas por el autor. El término, dada su importancia, se ha mantenido en la lengua griega desde Homero hasta el griego moderno, formando compuestos hoy con briso, brisiá etc. Chantraine, P. (1977). Dictionnaire étymologique de la langue grecque. Histoire des mots. Les Editions Klincksieck.

2 Este artículo es una contribución al Diccionario de Términos Filológicos de la Cultura Griega que diversos investigadores se encuentran elaborando; continuidad, complemento y ampliación del Diccionario. Conceptos Fundamentales de la Cultura Griega llevado a cabo por César García Álvarez (2017). Universidad de Chile. Centro de Estudios Griegos, Bizantinos y Neohelénicos.

3 Aunque aquí nos referimos a la hybris trágica, los griegos la proyectaban a toda situación antiética. Hipócrates nos dice que todo médico está llamado a tener, so pena de caer en hybris, conocimientos, habilidades y valores; en este último caso el Corpus Hipocraticus era particularmente exigente, léase el Juramento Hipocrático. Tratados Hipocráticos I. Edit. Gredos, Madrid 1983. David Owen distingue los siguientes síntomas del Sindrome de hybris: 1. Exceso de confianza en sí mismo; 2. Impaciencia constante; 3. Falta de atención a los detalles; 4. Creerse insustituible. Véase: Rev. Med. Chile, 2014; 142: 270-27: "Síndrome 
Hybris significa exceso, traspasar las capacidades humanas: exceso en Prometeo al enfrentarse a Zeus; pisar la alfombra roja destinada solo a los dioses, en el caso de Agamenón; la opresión que sufre Electra por parte de su madre Clitemnestra y el destierro de Orestes, es en las Coéforas, hybris; Xerxes, el de Los Persas, vive en estado permanente de hybris: cree en el poder absoluto de su imperio, en la impunidad al violar el Helesponto y, por sobre todo, saberse viejo, siendo joven, experimentado general siendo apenas aprendiz de intendencia; la sangre real no asegura éxitos. Antígona pone en escena dos hybris, la de Creontey la de Antígona, ambas camino de muerte; el caso de Edipo es paradigmático, porque no hay mayor hybris intelectual que creerse dueño de toda la verdad: desató el enigma de la esfinge, cierto; fue coronado por ello rey de Tebas; confió, además en la investigación del culpable, sin embargo, él, el sabio no sabía que estaba casado con su madre. Estos ejemplos nos perfilan ya la noción de hybris ${ }^{4}$ y nos ahorran demos otros más. Hybris es, en consecuencia: exceso, desmesura, soberbia, transgresión u orgullo que atraen un castigo ${ }^{5}$. Los griegos no tenían conciencia de pecado moral como sucedía en el mundo judeo-cristiano, pero sí de transgresión a la Moira, a la parte que a cada uno se le ha dado ${ }^{6}$ : ir más allá de sí mismo, desconocer la condición humana era precisamente caer en hybris. Uno de los sinónimos de hybris es

de Hybris: descripción y tratamiento", por Carlos Carvajal H. Departamento de Cirugía Oriente, Hospital del Salvador. Facultad de Medicina de la Universidad de Chile y Departamento de Cirugía, Clínica Las Condes. Santiago de Chile.

4 Aunque originariamente los griegos circunscribían la palabra hybris al comportamiento moral dado específicamente en el Mito de las Edades y su expresión en la tragedia, modernamente ha pasado a ser aplicada a los excesos de poder político, embriaguez de poder lo llama Bertrand Rassell y, aplicado a situaciones clínicas por la psicología, síndrome de hybris es el nombre que le aplica David Owen en El poder y en la enfermedad. El Ojo del Tiempo, Siruela, Madrid, en inglés Sickness and in Power, 2008.

5 Ricoeur, P. Finitud y culpabilidad, Madrid: Taurus, 1982. La megalopsychía es orgullo en Homero, pero sin el carácter de hybris, pues se trata de una aspiración natural a ser grande dentro de los propios límites.

6 Moira, de meros, es la parte o suerte que a cada uno se le ha dado. Homero llama a los hombres meropes. Merops fue el héroe de Cos salido de la tierra. Ops (voz, vista) es un componente de meropes, para que, aunque salidos de la tierra, tengamos voz y mirada, factores de cultura. 
ceguera, aquello que tanto acusa Tiresias a Edipo y lleva a éste a sacarse los ojos. Apolo desde su templo de Delfos imperiosamente prescribía:"Medén agan", nada demasiado; transgredir tal mandato "antihybrico" era atraer la ira de los dioses, la ira de Némesis, y desencadenar situaciones trágicas. Decía Heródoto: "Puedes observar cómo la divinidad fulmina con sus rayos a los seres que sobresalen demasiado, sin permitir que se jacten de su condición; en cambio, los pequeños no despiertan sus iras. Puedes observar también cómo siempre lanza sus dardos desde el cielo contra los mayores edificios y los árboles más altos, pues la divinidad tiende a abatir todo lo que descuella en demasia" .

Esta reiteración de los autores griegos en el mal amenazante de la hybris y la dureza de su castigo ¿no habrá sido causante, entre otras, del ideal ético y estético que gobernó la época clásica griega? No solo la autarkía y atarasia, también la sophrosyne e ideales de perfección - conceptos huyentes de la hybris- animaron la estatuaria de Fidas, Praxíteles y Mirón, hasta alcanzar la arquitectura del Partenón, Erectión o Templo de Atenea Nike Aptera. La tragedia, que se representaba públicamente, entregaba a los atenienses en el decir de Aristóteles (Poética) dos mensajes: por una parte, belleza formal y, por el otro, una dura compulsión de hybris. Ambos elementos caían y germinaban en el alma de los griegos la katharsis, un ideal superior de perfección. El mandato de Apolo "Medén agan" se derramó desde los altos montes de Delfos a toda Grecia; ninguna ética se sustrajo a tal principio, ninguna tesis moral: se vincularon con Apolo, Sócrates, Platón, Aristóteles, la axiología de Demócrito, estoicos y epicúreos ${ }^{8}$.

Entró la hybris en el mundo cuando en la era mítica se rompió la vinculación con los dioses - Edad Aurea- y apareció el ciclo de las edades:

7 Heródoto, Historia VIII.10.

8 No concuerda con esta idea Tucídides para quien el universalismo de la axiología clásica fue circunstancial, la constante humana es la hybris. Como dice Javier Picón Casas: "La conciencia axiológica de Heródoto al narrar Historiae ha desaparecido en Tucídides por completo", en "La noción de hybris en Critias de Platón", Areté. Revista de Filosofía XX, 1,208, p. 93. 
la de plata, bronce, héroes ${ }^{9}$ e hierro ${ }^{10}$. En la Edad de Oro no existía hybris, reinaba la diké, (la justicia) eusijoi (la paz); la raza áurea era calificada como os zeoi, semejante a dioses ${ }^{11}$. La tragedia estaba excluida de esta Edad, aparece con el inicio de las cuatro edades degradantes humanas: plata, bronce, héroes y hierro. Cada una de estas edades llevaba enquistada en su corazón una hybris: la impiedad humana es de la Edad de Plata, Agamenón no tuvo piedad de su hija Ifigenia; hybris de impiedad religiosa es la de los hombres de la Edad de Bronces: Prometeo y Creonte, se levantaron contra las divinidades; los hombres de la Edad de los Héroes viven en medio de la guerra que es ya en sí y por sí hybris; ¿es fácil practicar la diké en tiempos bélicos? Los troyanos representaron en la Guerra de Troya el triunfo de la hybris y los aqueos el de la diké; sin embargo, en Las Troyanas observamos que los aqueos aparecen pervertidos de hybris bélica. Es muy difícil ser vencedor y ser justo y hasta mandar y ser justo ${ }^{12}$. En la Edad de Hierro, todo está recubierto por la hybris.

\section{2.- La hybris en Homero}

En la Ilíada (Canto I) - epopeya que los niños griegos sabían de memoria-en sus 24 cantos y 15.674 versos, los niños descubrian ${ }^{13}$ qué era la funesta hybris: Agamenón en un exceso de atribución, desea contra su

9 Sobre el qué y por qué Hesíodo introduce entre las edades de Bronce e Hierro la de los Héroes, rompiendo la degradación metálica, véase: Jean-Pierre Vernant, Mito y pensamiento en la Grecia antigua. Ariel, Barcelona, 1973.

10 Hesíodo en Los trabajos y los días.

11 Sobre el tema de los dioses, tan presente en Homero y en los trágicos griegos, si son en realidad una invención poética de Homero (G.Thiele), presencia cultural representando lo mejor de nosotros (Ortega y Gasset) o verdadera teología mística (Buffiére), remitimos a:G.Thiele, Homero y su Ilíada, Caracas 1969, p.91; F. Buffiére, Les mythes d'Homére et la pensée grecque, Paris 1973, pp.411-415 y quien hace un acucioso examen del concepto de "deidad" griega, sin tomar partido por la tesis de Thiele o Buffiére, es Carlos Espejo Muriel en "Religión e Ideología" en Studia Histórica II (1994).

12 La afirmación es válida para todo el que manda. Es ya dicho popular: " $E l$ poder y el dinero corrompen".

13 Usamos aquí el "descubrir" en el sentido que Platón concede a los mitos: traer del olvido lo que ya preexistía en el alma. Aristóteles resta importancia al mito, que lo ve solo como persuasivo, aunque lo valore en Metaphysica, , , 1074b3-13 
voluntad hacer suya a Criseida la hija del sacerdote Crises; Apolo castiga con una peste tal desmesura (hybris), una peste se desencadena sobre el ejército. Agamenón, escarmentado, devuelve a Criseida al sacerdote Crises, pero opta por otro arrebato, otra hybris, hacer suyo el botín propio de Aquiles. El castigo de esta nueva hybris es sabido: Aquiles, el mejor, se retira del ejército siendo dañado éste por los troyanos de modo ostensible. En el Canto IX, tras la embajada de Ulises, Fénix y Áyax para convencer a Aquiles deponga su enojo y se integre al ejército aqueo, disminuido por la exitosa acción de los troyanos, la respuesta del hijo de Peleo fue de franca hybris: "Tienes un corazón cruel y soberbio", le dice Áyax antes de retirarse. El Canto XVI nos presenta otro ejemplo aleccionador de hybris: Patroclo se lanza a la batalla haciendo caso omiso del consejo de sophrosyne o prudencia que Aquiles le había dado: se acercó demasiado al bando enemigo - hybris- y fue herido por Euforbo y muerto ${ }^{14}$.En el Canto XXII, la hybris es de Héctor, quien desobedeciendo el consejo de prudencia de su padre Príamo y su madre Hécuba, se lanzó lleno de fatal hybris sobre Aquiles a cuyas manos muere ${ }^{15}$.

No obstante tales evidencias homéricas, conviene precisar qué se entiende realmente por la llamada hybris homérica. La lectura de "La psicología homérica" de José S. Lasso de la Vega ${ }^{16}$ nos obliga a hacer algunas reservas sobre el término hybris en Homero. Entendamos que en tiempo de Homero "no conocemos una palabra que podamos traducir por alma" y el alma es la depositaria de la hybris. Pero vengamos a la palabra "cólera", sinónimo de hybris: se entendía por cólera la agitación del diafragma (fren, frenes) unida a la agitación de la respiración, jadear (Il. II.24); términos vinculados con "thumos", primitivamente aliento "y fuente de impulsos irracionales" (Lasso de la Vega, p.247). Al no existir una convalidación de la psicología homérica por la del siglo V a.C. y menos por la de hoy, hay que entender a Homero en sí mismo sin hacer mayores

14 La prudencia junto con el coraje, la sabiduría y la justicia constituyen la idea de felicidad en Homero. Véase Carlos Espejo, op. cit.

15 Conviene precisar que en Homero las acciones se tildan de kalá (hermosas) y aisjrá (feas), término este último que evolucionará en su contenido a "injustas" y que en la tragedia se calificarán ya de hybris, aunque las palabras de Antígona recordarán el significado homérico en aquella frase con que replica a Creonte: "Sí he de morir, moriré con una muerte bella".

16 Lasso de la Vega, José S (1963). Introducción a Homero I, Barcelona, Labor. 
extrapolaciones.

Por otra parte, hybris en cuanto exceso, deja afuera la capacidad combativa del guerrero homérico para defender su casa, estirpe o feudo, antes bien, era tenido ello por areté. No podía ser de otro modo, pues la casa o ascendencia del héroe se vinculaba con los dioses: Lasso de la Vega nos da múltiples ejemplos, comenzando por Aquiles hijo de la diosa Tetis, Sarpedón hijo de Zeus y otros. Tal vinculación con los dioses los inserta ya de algún modo en la Edad de Oro, donde no había hybris. El héroe homérico podrá ser imprudente, pero no cometer hybris, su cualidad es tener siempre agathos y areté, incluso, podrá cometer kakós, pero no es kakós. Hybris en Homero es kakós.

Con respecto a la justicia, que los trágicos griegos relacionan tan directamente con la hybris, en Homero existe dikeosyni, pero no es problema central, sino la areté guerrera. Los excesos de los Cíclopes no son calificados por Homero como hybris, sino como athemistoi, contrarios a Temis, contrarios a lo que correspondía hacer en ese momento, lo debido a los compañeros de Ulises, lo regular, lo justo, así M. Ruipérez ${ }^{17}$. Por otra parte, hybris está relacionada con la noción de derecho, "le terme ayant une valeur juridique" ${ }^{\prime \prime}$, ciertamente muy poco desarrollado en la época homérica, y preocupación central en la tragedia de Esquilo y Sófocles como respuesta a una época democrática que siempre exigía leyes y normas claras $^{19}$. Hasta se puede decir que el problema de Esquilo y Sófocles fue claramente legal: suplir la ley de sangre en Esquilo e instauración del Areópago y prevalencia de la ley positiva o la de los dioses, tesis de Antígona. No es tema de este lugar desarrollar más este tema, remitimos a L. Gernet ${ }^{20}$. La hybris como desencadenante de tragedia supone lo que

17 Ruipérez, M. "Historia de Thémis en Homero", en Emerita 28 (1960), pp. 103 y l12.Más sobre Themis y las diferencias con G. Glotz, Histoire Grecque, I, 1925, p. 118; citado por H. Frisch, Might and Right in Antiquity, from Homer to the Persian Wars, Kobenhaun 1949, p. 38.

18 Chantraine, P. (1977). Dictionnaire étymologique de la langue grecque. Histoire des mots. Les Editions Klincksieck.

19 Garcia, César (2016). "Tragedia, filosofía y política en Esquilo" en Revista BYzantion Nea Hellás (Anuario).

20 Gernet, L. "Jeux et droit. Remarques sur le XXIII chant de

I' Iliadc", CRAI (1947), pp. 572-574. 
Dodds llama la "cultura de la culpa", superación de la "cultura de la vergüenza", culpa que se hace heredada como en Esquilo (Orestía) y en Sófocles (Edipo, rey y Antígona) ${ }^{21}$.

\section{3.- La hybris en los trágicos griegos}

a) Esquilo. La hybris en Esquilo ha de entenderse dentro de la teología que sustenta toda su tragedia. El mundo para Esquilo está ordenado en justicia y cuanto lo altera es hybris, que reclama el dolor hasta que tal orden se restablezca. Dolor y hybris son correlativos. El dolor no es el resultado de un azar, tiene una causalidad moral vinculada con la divinidad. Si comparamos la hybris en Esquilo y en Homero, se advierte en la epopeya una desmesura bronca, primitiva, poco legal. Esquilo pide para sus héroes como lo hace Homero, fama, pero tal anhelo de gloria está en el autor de la Orestía ajustado a una idea de una justicia exigente, no en vano deriva la "ley de sangre" a la "ley del Areópago" y las Erinnias se convertirán en Euménides. La hybris de los campos troyanos de batalla tienen menos exigencias que la de la "polis", pues el camino hacia la democracia se encuentra aún muy lejos. La palabra pólemos. que anida en Homero y en Esquilo, tras cuatro siglos de distancia entre ambos ya no suenan igual ${ }^{22}$.

b) Sófocles. En Sófocles la hybris no nace de un orden divinamente sometido a justicia y traicionado, sino de la debilidad humana instalada por la tuxe, el destino. En Edipo, rey todos los excesos originados por la muerte de Layo, los que nacen de la soberbia intelectual de Edipo y los rechazos y acusaciones a Creonte y Tiresias, constituyen tres cabezas de la hybris que se anudan y estrangulan en el verso 1080 cuando dice: "en verdad, yo soy hijo de la Fortuna"23. A partir de este momento, la palabra tuxe solo aparece dos veces en la obra, porque Edipo, tras vaciar la órbita de sus ojos, ha entrado en la necesaria moderación. La hybris en Edipo, rey no se da de una vez para siempre, son ríos funestos que en la obra con cada nuevo impulso de solución más se enrarece la solución hasta el punto que a

21 Dodds, E. (1981). Los Griegos y lo irracional, Madrid.

22 García, César (2016). "Tragedia, filosofía y política en Esquilo", en Byzantion Nea Hellás $\mathrm{N}^{\circ} 35$, pp. 62 a 79.

23 Edipo, rey, verso 1080. 
más investigación por parte de Edipo, más se hunde en sus propios excesos o hybris. La hybris en Esquilo era traicionar un orden jurídico externo, en Sófocles es traicionarse a sí mismo y, si Esquilo era doctrinal Sófocles es psicológico, allí en Esquilo la culpa al final se limpia y el mundo ordenado se restablece, aquí en Sófocles el hombre aparece como un ser arrojado: El dolor de su hybris lo acompañará siempre, así en Edipo en Colono, Antígona y Los siete contra Tebas, no hay exultaciones y cantos finales como en las Euménides.

c) Eurípides ${ }^{24}$. La hybris en todos los trágicos se origina en último término por la imposición de la irracionalidad sobre la racionalidad (de los dioses, de la physis o jurídica). ¿Cómo se sitúa Eurípides ante esta triple racionalidad helena? Eurípides extrema, eleva la aguja de la irracionalidad al punto más alto; el ritmo pausado de Esquilo, el equilibradamente humano de Sófocles, aquí en Eurípides se exaspera y su tragedia y su hybris ascienden hasta la locura en Medea y la excitación en las Bacantes. Si las mujeres son más excitables que los hombres -no digo histéricas, como señala Freud- Eurípides lleva a escena mujeres incluso como coro. En el coro las hybris de las mujeres se hace sumatoria, hasta el punto que, no cabe ya su exasperación en las estrechas calles de la polis de Tebas y han de refugiarse en el campo abierto del Citerón. La verdad es que Maratón y Salamina en tiempo de Eurípides quedaban ya muy lejos y la guerra del Peloponeso muy cerca. Todo lo anterior acaso lo resuma este texto de Medea:

“¡Oh desgraciada de mí por mi orgullo! En vano, hijos, os he criado..."

"Mi corazón desfallece, cuando veo la brillante mirada de mis hijos. No podría hacerlo. Adiós a mis anteriores planes. Sacaré a mis hijos de esta tierra"

"Pero, ¿qué es lo que me pasa? ¿Es que deseo ser el hazmerreír, dejando sin castigar a mis enemigos? Tengo que atreverme."

“¡Ay, ay! ¡No corazón mío, no realices tal crimen! ¡Déjalos, desdichada! ¡Ahorra el sacrificio de tus hijos! Aunque no vivan conmigo, me servirán de alegría"

24 Remitimos a nuestro estudio "Para la comprensión de la tragedia. ¿Quién es Dioniso?" en Byzantion Nea Hellás № 36, 2017. 
"Es de todo punto necesario que mueran y, puesto que lo es, los mataré yo que les he dado el ser"25.

Los términos en que se expresa Medea son de manifiesta hybris, como el imperialismo de la Atenas de Eurípides desbordaba ya la naturaleza propia de la polis. Ir contra la propia naturaleza, queda dicho, era cometer hybris y atraía la venganza de los dioses. Los dioses de Grecia estaban ensayando ya las armas para castigar a Atenas con una guerra y Tucídides afilaba su pluma para escribir sus ocho libros sobre la Guerra del Peloponeso ${ }^{26}$.

Pero la hybris en Eurípides es más compleja: como en el caso de Antígona hay dos excesos, el de Penteo y el de Diónisos, con una diferencia, en el caso de las Bacantes es el dios Diónisos; el oponente es Penteo, un tirano como lo fuera Creonte en Sófocles ${ }^{27}$. Diónisos desde su excitación hybrica saltará no a la muerte, como sí sucede con Penteo, sino a la liberación, pues Diónisos es un dios soterós, salvador: mediante la excitación logra una purificación catártica, hace que por unos momentos el ser humano se olvide de sus limitaciones y miserias ${ }^{28}$. Diónisos es un dios bifronte, su hybris salva y condena.

\section{4.- Las etapas de la hybris en Platón}

Platón se refiere a la hybris en Fedro, Leyes y Critias $^{29}$. Platón dice en Fedro: "Un deseo desordenado y poco reflexivo nos lleva al placer, a esto se le llama hybris”. La hybris para Platón supone tres etapas: 1)

25 Eurípides, Medea, en: Alberto Medina González y Juan Antonio López Férez, Tragedias, Eurípides vol. I, Gredos, Madrid, 1983, pp. 250-25.

26 No entramos en la cuestión tucidídea, si la división fue obra de los editores posteriores o si está conclusa como quieren Herman Müller-Strübing y Franck Ezra Adcock o inconclusa; ya Amiano Marcelino en su siglo, IV d.C. consideraba que el libro VIII no pertenecía realmente a Tucídides. Quede esto para historiadores.

27 Véase Vilchez, Mercedes (1993). El dionisismo y las Bacantes. Universidad de Sevilla.

28 Véase Dodds, op. cit., p.81, ed.1982.

29 Platón, Critias, en: Burnet, J. (ed.), Platonis Opera, Oxford: Oxford University Press, 1905, 106a-121a. 
deseo desordenado de placer; 2) ofuscación del pensamiento y 3) deseo de engendrar descendientes. En Leyes alaba a los espartanos por no haber en ellos estas tres cosas: no se ve en ellos banquetes, símbolo del placer, placer que obnubila el pensamiento y hace del hombre un animal excitado por sus instintos; expresamente señala: "No tienen banquetes ni cuantas otras cosas acompañan a éstos excitando a más no poder todos los deleites". Los espartanos para Platón estarían más cerca de la sophrosyne, moderación, concepto opuesto a hybris y camino hacia la felicidad ${ }^{30}$.

Platón, por otra parte, ejemplifica la llamada "ofuscación de pensamiento" con la crítica a la democracia; la democracia es un sistema que filtra la hybris a través del cambio del significado normal de las palabras reinterpretándolas con manipulación, así: a la "audacia irreflexiva" la llama "lealtad al partido"; a la "prudencia", "cobardía"; a la "moderación", "máscara para encubrir la falta de hombría"; a la "inteligencia", incapacidad para la acción"; a la "precipitación", "condición viril";"“al hábil", "inteligente" etc. etc. No es necesario abundar más en este orden de oposiciones, pues nuestra sociedad tiene un diccionario mucho más amplio.

\section{5.- Sophrosyne y hybris en grandes personalidades políticas griegas: Pericles y Alejandro}

Sophrosyne e hybris también se dieron en grandes personalidades políticas, una fue Pericles la otra Alejandro Magno; figuras contrapuestas ambas encarnan los conceptos señalados. Javier Picón Salas resume así el pensamiento del autor de "La guerra del Peloponeso" y su ideal sophrosyne en Pericles: "Pericles queda retratado como el garante del espíritu de moderación de los viejos tiempos, pues asustaba a quienes se mostraban arrogantes y animaba a quienes se encontraban abatidos. La dependencia ateniense de este hombre de Estado fue tal que Tucídides dice que Atenas era nominalmente una democracia, pero en la práctica se trataba del gobierno del primer ciudadano. Siendo sus sucesores todos parecidos y ambicionando cada uno ser también el primero, sacrificaron todos los asuntos a la adulación del pueblo y arruinaron la polis. La vinculación de Pericles con el temor a los dioses y el respeto a los antepasados resulta aqui dificil de rebatir"'

30 Platón trata la sophrosyne de modo particular en Cármides.

31 O. cit. nota:5. 
Es pensamiento de Aristóteles que el intelecto, chispa divina en el hombre, es capaz de controlar su propia persona y, por consiguiente, de nosotros depende mantener la serenidad o sophrosine y, desde ella la autarquía, ajena a los excesos. Se podrá decir, pero ¿cómo Aristóteles pudo mantener silencio ante las desmesuras de su alumno Alejandro? ${ }^{32}$ Aristóteles es un filósofo no pragmático, actúa siempre en forma teórica, descriptiva; así lo hace en la tragedia al manejar diversos términos: hybris, por ejemplo, se relaciona con amartía, error trágico y con anagnórisis, momento de reconocimiento del error y cambio de peripecia o inversión de próspera en adversa fortuna, siendo la palabra esencial para Aristóteles en la tragedia katharsis. Resulta extraño que un filósofo de la talla de Aristóteles se quede en lo formal de la tragedia y eluda el tema señalado más arriba, la fuerza de la hybris en la tragedia clásica. Ciertamente Aristóteles plantea el tema de la hybris en la anagnórisis, no podía ser de otro modo, pero lo formaliza desvitalizándolo, extrayéndole la correlación delito-castigo y su gran marco mítico-religioso.

Entendamos un poco más el problema: en la época de Aristóteles la tragedia ya no se representaba y la cosmovisión ético-religiosa era ya otra. Aristóteles por ésta y otras razones examina la tragedia con ojos analíticos de psicólogo, la examina por el efecto catártico que produce. En la Ilustración, época a la que pertenece Aristóteles, los hombres sienten que los grandes temas mítico-religiosos que envolvían la hybris en Esquilo y Sófocles, quedan ya muy al fondo. Transgresión y hybris ya no se sienten correlacionados como en el siglo V. Era la época de la comedia de Aristófanes y sobre todo Menandro. Aristóteles se margina en lo conceptual, así pues, de su discípulo Alejandro y elabora el deber ser en su Ética, deber ser que la libertad puede traicionar.

32 No es necesario dar ejemplos: se creía el nuevo Aquiles encarnado; a cincuenta ciudades dio su nombre; quien portaba su efigie recibía todos los dones. 


\section{Referencias bibliográficas}

ARISTÓTELES. Metaphysica, $8,1074 \mathrm{~b} 3-13$

BUFFIÉRE, F. (1973). Les mythes d'Homére et la pensée grecque, Paris.

CARVAJAL, C. (2014)."Síndrome de Hybris: descripción y tratamiento". Rev. Med. Chile, 2014; 142: 270-27.

CHANTRAINE, P. (1977). Dictionnaire étymologique de la langue grecque. Histoire des mots. Les Editions Klincksieck.

DODDS, E. (1981). Los griegos y lo irracional. Madrid.

ESPEJO MURIEL, C. (1994), en "Religión e Ideología" en Studia Histórica II.

EURÍPIDES (1983). Medea, en Alberto Medina González y Juan Antonio López Férez, Tragedias, Eurípides vol. I. Gredos: Madrid.

FRISCH, H. (1949). Might and Right in Antiquity, from Homer to the Persian Wars. Kobenhaun.

GARCÍA, C. (2016). "Tragedia, filosofía y política en Esquilo”, en Byzantion Nea Hellás 35.

--- (2017). Conceptos Fundamentales de la Cultura Griega. Centro de Estudios Griegos, Bizantinos y Neohelénicos. Universidad de Chile.

GERNET, L. (1947). «Jeux et droit. Remarques sur le XXIII chant de I'Iliadc., CRAI.

GLOTZ, G. (1925). Histoire Grecque, I.

HIPÓCRATES (1983) Tratados Hipocráticos I. Gredos: Madrid.

HERÓDOTO, Historia VIII.10.

HESÍODO. Los trabajos y los días.

LASSO DE LA VEGA, J. S. (1963). Introducción a Homero. Labor: Barcelona.

OWEN, D. (2008). En el poder y en la enfermedad. El Ojo del Tiempo, Siruela, Madrid; en inglés Sickness and in Power, 2008.

PICÓN SALAS, J. (2008). "La noción de hybris en Critias de Platón", Areté. Revista de Filosofía XX, 1.

PLATÓN (1905). Critias, en: Burnet, J. (ed.), Platonis Opera, Oxford: Oxford University Press.

RICOEUR, P. (1982). Finitud y culpabilidad. Taurus: Madrid.

RUIPÉREZ. M. (1960) "Historia de Thémis en Homero", en Emerita 28.

SÓFOCLES. Edipo, rey, verso 1080.

THIELE, G. (1969). Homero y su Ilíada. Caracas.

VERNANT, J-P. (1973). Mito y pensamiento en la Grecia antigua. Ariel: Barcelona.

VILCHEZ, M. (1993). El dionisismo y las Bacantes. Universidad de Sevilla: Sevilla. 